\title{
LA POLÍTICA ESPAÑOLA HACIA EL MAGREB Y ORIENTE MEDIO. PRIMAVERA ÁRABE ${ }^{1}$
}

\author{
Román Reyes ${ }^{2}$ \\ President of the EMUI_EuroMedUniversity
}

http://dx.doi.org/10.5209/rev_NOMA.2013.v39.n3.48318

\begin{abstract}
Resumen.- Se acusa a España de que ha cambiado de chaqueta. Lo que no se sostiene. Los mensajes de España han sido claros e inequívocos. Algo que puede comprobarse en los registros que estos mensajes han forzado. Tanto a nivel de literatura como en comportamientos. Las propuestas comunitarias de diálogo coinciden con los valores que España viene defendiendo. Su posición teórico-ideológica ha sido siempre homogénea. Coincidente con la de la comunidad euroárabe: cooperación e integración regional.
\end{abstract}

Palabras clave.- Magreb, Oriente Medio, Primavera Árabe

Abstract.- To Spain is accused of having changed sides. What does not hold. Spain messages are clear and unambiguous. Something that can be seen in the records that have forced these messages. At both literature and behaviors. EU proposals for dialogue match the values that Spain has defended. His theoretical - ideological position has always been consistent. Coincident with the Euro-Arab community, regional cooperation and integration.

Keywords.- Maghreb, Middle East, Arab Spring

A mí, Hasan, hijo de Mohamed el alamín, a mí, Juan León de Médicis, circuncidado por la mano de un barbero y bautizado por la mano de un papa, me llaman hoy el Africano, pero ni de África, ni de Europa, ni de Arabia soy. Me llaman también el Granadino, el Fesí, el Zayyati, pero no procedo de ningún país, de ninguna ciudad, de ninguna tribu. Soy hijo del camino, caravana es mi patria y mi vida la más inesperada travesía. (Amin Maalouf, León el africano)3.

\footnotetext{
${ }^{1}$ Quede constancia de mi agradecido reconocimiento a Borja Fontalva, Doctor en Relaciones Internacionales y Coordinar General del EMUI_EuroMed University, que ha leido el texto y me ha hecho valiosas observaciones. En su haber es obligado cargar también la actualización de la biografía y la revisión de las notas o aparato crítico.

${ }^{2}$ Román Reyes es Licenciado y Doctor en Filosofía, Licenciado y Doctor en Ciencias Políticas y Sociología. Catedrático de Ciencias Sociales y Jurídicas en la Universidad Complutense de Madrid, desde 1975 explica Filosofía y Ciencias Sociales, y Sociología del Conocimiento y de la Cultura. Exbecario Max-Planck en el Institut für Sozialforschung, Frankfurt M., funda en el año 2007 el Instituto Universitario de Investigación Euro-Mediterranean University Institute EMUI_UCM, que desde entonces dirige, soporte del EMUI_EuroMed University (Union for the Mediterranean), con sede en Lecce-Salento (Italia), institución de la que es su actual Rector. Ha publicado 27 libros, entre los que destaca el Diccionario Crítico de Ciencias Sociales, 4 vol, Ed. Plaza y Valdés, Madrid-México 2009 ss. y un centenar de artículos en revistas científicas. Fundó y desde entonces viene dirigiendo las siguientes publicaciones periódicas: Nómadas. Revista Crítica de Ciencias Sociales y Jurídicas, ISSN ISSN 1578-6730, publicación científica de la UCM, Madrid 1999 ss, y Nomads. Mediterranean Perspectives, ISSN 1889-7231, Edición bilingüe: Inglés con traducción a otra lengua de la UE o de la zona EuroMed, Plaza y Valdés, Madrid-México 2009 ss, órgano oficial del EMUl.

3 "(...) Mis muñecas han sabido a veces de las caricias de la seda y a veces de las injurias de la lana, del oro de los príncipes y de las cadenas de los esclavos. Mis dedos han levantado mil
} 
España, el término 'España' no abarca por entero la realidad proteiforme de la Península. También es un mito, una palabra que ha envejecido y contra la cual el escritor debe emprender la guerra: una guerra desigual, un combate contra las quimeras, parecido al que libró el caballero don Quijote contra los amenazantes molinos de viento. (Juan Goytisolo, España y los españoles)4

Mi mirada no es, ni puede ser, la de un experto en Relaciones Internacionales. Desde mi posición de sociólogo crítico y desde mi estatus de gestor de un Centro Superior EuroMed, utilizo el resultado de la investigación de los primeros, así como la literatura especializada que, al respecto, circula.

Mi mirada que no pasa de ser una aproximación sociológica y literario-cultural al sugestivo panorama que la tensión mediterránea supone y a las pasiones que esa tensión genera. Respetando la movilidad y flujos Norte-Sur, pero especialmente horizontal, en el Norte o hacia el Norte, con la Unión Europea como telón de fondo.

Para redactar este trabajo he consultado no sólo con teóricos de las Relaciones Internacionales. Me ha sido enriquecedor escuchar también el relato de la experiencia de quienes, desde la política o la diplomacia, generan otra perspectiva menos filtrada, al estar en contacto con la realidad cambiante con la que a diario se enfrentan. Aunque el registro de éstos sea plural, como plural es la perspectiva de cada uno mirando lo mismo. Lo que enriquece el resultado.

velos, mis labios han sonrojado a mil vírgenes, mis ojos han visto agonizar ciudades y caer imperios. Por boca mía oirás el árabe, el turco, el castellano, el beréber, el hebreo, el latín y el italiano vulgar, pues todas las lenguas, todas las plegarias me pertenecen. Mas yo no pertenezco a ninguna. No soy sino de Dios y de la tierra, y a ellos retornaré un día no lejano. $Y$ tú permanecerás después de mí, hijo mío. Y guardarás mi recuerdo. Y leerás mis libros. Y entonces volverás a ver esta escena: tu padre, ataviado a la napolitana, en esta galera que lo devuelve a la costa africana, garrapateando como mercader que hace balance al final de un largo periplo. Pero no es esto, en cierto modo, lo que estoy haciendo: qué he ganado, qué he perdido, qué he de decirle al supremo Acreedor? Me ha prestado cuarenta años que he ido dispersando a merced de los viajes: mi sabiduría ha vivido en Roma, mi pasión en el Cairo, mi angustia en Fez, y en Granada vive aún mi inocencia" (Amin Maalouf, León el africano)

${ }^{4}(\ldots)$ "Y, sin embargo, el mito existe: ahí está, fruto de la laboriosa elaboración del tiempo. En nombre de este mito la casta militar de Castilla se impuso a las minorías divergentes y a las zonas periféricas de la Península a finales del siglo XV. Bajo los Reyes Católicos, el ideal castellano, religioso y guerrero, lleva sucesivamente a la unidad nacional, a la desaparición del último reino árabe, a la expulsión de los judíos, al descubrimiento y a la conquista de América, a las guerras religiosas emprendidas en Europa en nombre de la Contrarreforma. Es un mito que, por su poder, produce un milagro comparable al de la victoriosa guerra santa de los árabes iluminados por la palabra de Mahoma: durante más de un siglo, la realidad parece ceder y doblegarse ante su sola presencia, y, en los dominios españoles de Felipe II, "jamás se pone el sol". Asombroso vigor del mito, que sobrevive a la ineluctable decadencia del poder militar español. Los españoles más clarividentes, empezando por Quevedo, comprueban la ruina del país: ruina provocada por el mito, cierto, pero ruina gloriosa, embellecida a su vez por el mito y sostenida por él. En medio de una realidad decrépita, que se deteriora más y más, el mito se mantiene intacto y no quiere echarse atrás. Mito sin duda condenable, pero mito generador de distinciones y diferencias: abismo infranqueable entre España y el resto del mundo, circunstancia elevada a la categoría de "esencia". Unamuno, y en general toda la generación del 98, se mantendrán, en el plano estético, fieles a esta identificación arbitraria, y en 1936, la mitad de los españoles se alzarán, una vez más, para defenderla, atrincherados detrás del mito como tras su última razón de ser". (Juan Goytisolo, España y los españoles) 
El Mediterráneo es ciertamente frontera. Pero, al mismo tiempo, excluyente pretexto para un diálogo o convergencia que muchos consideran imposible. Yo, sin embargo, pienso que las bases para ese diálogo ya existen.

Los protagonistas son no sólo los gobiernos implicados y los variados intereses que representan. Las políticas que esos gobiernos diseñan y aplican no tendrían legitimidad sin ese recurrente pronunciamiento de la ciudadanía, que se manifiesta de las formas más plurales y heterogéneas posibles.

La lengua, las lenguas y especialmente las hablas, el uso que de esas lenguas se haga y la interpretación de los discursos en los que se apuntalan, no es el problema. Ni siquiera una disculpa para aplazar un diálogo y un entendimiento a todos los niveles: religioso, cultural, político, económico y cultural.

Cuando se conoce de cerca la política exterior española nadie se sorprende de que condicione la política europea hacia el Mediterráneo. España comprende bien el problema. Es de interés prioritario. Especialmente, el diálogo político que, con matices, es común a España, Francia e Italia, que mantienen, en materia de Derechos Humanos, discursos más centrados que el resto de países de la UE.

Se acusa a España de que ha cambiado de chaqueta. Lo que no se sostiene. Los mensajes de España han sido claros e inequívocos. Algo que puede comprobarse en los registros que estos mensajes han forzado. Tanto a nivel de literatura como en comportamientos. Las propuestas comunitarias de diálogo coinciden con los valores que España viene defendiendo. Su posición teóricoideológica ha sido siempre homogénea. Coincidente con la de la comunidad euroárabe: cooperación e integración regional.

\section{Primavera Árabe}

C'est un garçon sans importanve vollective, c'est tuot juste un individi. (Luis Feridinad Céline, L'Église) $^{5}$

¿Hay que ser sultán para comprender que, en los 4 confines y en los 7 climas del mundo, todos los hombres se parecen?. ¿Acaso la prueba más concluyente de que los hombres de todas partes son idénticos no consiste en que cada uno puede ocupar el lugar del otro?. (Orhan Pamu, El astrólogo y el sultán)

Siempre que pienso en Mohamed Buazizi ${ }^{6}$ me viene a la memoria la cita de Céline con la que Sartre inicia La Náusea ${ }^{7}$. Nadie había previsto que la

\footnotetext{
${ }^{5}$ Joven tunecino de 28 años, universitario en paro, vendedor ambulante, de quien dependía el sustento de su madre viuda y de sus hermanos, se inmoló a lo bonzo, en público, ante la sede del Gobierno Provincial de la ciudad de Sidi Buzil, una fría mañana del 17 de diciembre del 2014 Fue involuntariamente la chispa, l'étincelle, que encendió la revuelta o revolución. el mártir que vino con la primavera (Sidi Bouzid, 29 de marzo de 1984-Ben Arous, 4 de enero de 2011),

${ }_{7}^{6}$ Mohamed Buazizi

7 Jean-Paul Sarte, La Nausée, Gallimard, Paris1938
} 
autoinmolación en Túnez de un pobre e 'insignificante' joven de 28 años se convirtiera en 'la crispa', 'l'étincelle' que pusiera voz y acción a una palabra durante décadas reprimida: 'basta'. Trágico momento que me resisto a interpretar por aquello de 'es necesario que un hombre muera por el pueblo ${ }^{8}$. Esa latente voluntad silenciada, aparentemente dormida, de la ciudadanía, se convirtió de repente en un indignado 'kifaya', que se iba a tener su inmediato eco en la población joven de la gran mayoría del mundo árabe.

Porque Mohamed Buazizi supo invocar su condición de 'individuo' cuando las condiciones ya se daban, su 'martirio' será recodado como ese punto de no retorno, que ha transformado el mapa político y social de la zona, con repercusiones internacionales que el resto de los países no había previsto. Al menos no esperaban que sucediera con la celeridad y aparente improvisación como sucediera. Del 'basta ya' era fácil perder el miedo y gritar 'lárgate', 'dégage', ante las puertas de la repugnante y provocadora ostentación de suntuosas residencias o palacios de dictadores, tiranos, iluminados ..., o desde donde diseñaban escenarios de recreación y sumisión en los países que tiranizaban y que habían convertido en sus feudos privados.

Probablemente Mohamed Buazizi fue un 'loco', como lo fuera, en otro sentido y consecuencias más perversas, la 'locura' del magnicida Gavrilo Princip, que desencadenó la I Guerra Mundial. Pincip, sin saberlo, provocó una reacción en cadena al asesinar el 28 de Junio del 2014 en Sarajevo al emperador Francisco Fernando de Austria y a su esposa Sofía. Buazizi, sin embargo, nunca llegó a saber que iba a convertirse en un 'mártir'. Con su acto más que simbólico estaba reclamando lo que ya consideraba para él y su familia inalcanzable: libertad, justicia, dignidad.

Al igual que la Primera Guerra Mundial brindó una triste demostración de que los elevados ideales y las nobles intenciones traducidas en legislaciones no quedan exentas de poder sufrir la ley de los efectos secundarios, en los países árabes se vive ahora un proceso de adaptación, a menudo sangriento, y con la incertidumbre como tensión que sufren los pueblos afectados.

Tal vez convendría recordar lo que advertían Georges Washington y Thomas Jefferson a la hora de redactar la Constitución de EEUU: el hándicap que, a propósito de 'las grandes alianzas' previas, la heterogeneidad de la Primavera

\footnotetext{
${ }^{8}$ Carta de Salvador Espriu a Manuel Sacristán: "A vegades és necessari i forçós / que un home mori per un poble, / però mai no ha de morir tot un poble / per un home sol:/ recorda sempre això, Sepharad. / Fes que siguin segurs els ponts del diàleg / i mira de comprendre i estimar / les raons i les parles diverses dels teus fills. / Que la pluja caigui a poc a poc en els sembrats / i l'aire passi com una estesa mà / suau i molt benigna damunt els amples camps. / Que Sepharad visqui eternament / en l'ordre i en la pau, en el treball, / en la difícil i merescuda / llibertat". || "A veces es necesario y forzoso / que un hombre muera por un pueblo, / pero nunca ha de morir todo un pueblo/ por un solo hombre:/ recuerda siempre esto, Sepharad. / Haz que sean seguros los puentes del diálogo/ e intenta comprender y amar / las razones y las diversas hablas de tus hijos. /Que la lluvia caiga poco a poco en los sembrados / y el aire pase como una mano tendida / suave y muy benigna sobre los anchos campos. / Que Sepharad viva eternamente / en el orden y en la paz, en el trabajo, / en la difícil y merecida / libertad" (Traducción de Carlos Vitale). Sepharad es el nombre mítico usado por Espriu para hacer referencia a España o a la Península Ibérica. (Salvador López Arnal: "Cartas de Salvador Espriu a Manuel Sacristán sobre lógica, solidaridad, Giulia Adinolfi y una cátedra universitaria". En Rebelión, 2009): http://www.rebelion.org/noticia.php?id=80234, consultado el 28 de junio del 2014
} 
Árabe supone para la fijación de textos constituyentes sobre la base de las demandas que el movimiento reivindica. $Y$ esas 'alianzas previas' tienen, obviamente, que tener en cuenta no sólo las relaciones bilaterales entre Egipto e Israel. También importa el papel, formal o efectivo que han jugado las potencias occidentes a la hora de defender sus intereses en la zona. Bajo el paraguas o no de la Nueva Alianza para el Desarrollo de África (NEPAD), la Unión Africana (2001) o esa Unidad Arabe y Panafricana que pretendía liderar el excéntrico dictador Muammar Gadaffi.

Se trata de un proceso inesperado, no predecible. Hay consenso a la hora de entenderlo así. Y España se adapta a este proceso porque está en consonancia con los valores que hasta ahora viene defendiendo. Para esta adaptación España toma especiales medidas de acompañamiento. Al mismo tiempo, no le es difícil adaptarse a la nueva situación. A pesar de que este movimiento se desarrolla posteriormente con desigualdad. Es heterogéneo a la hora de hablar del rumbo que, en cada país, ha ido fijando. Es, sin embargo, evidente que en ninguno de los países árabes afectados se optó por el modelo de transición española. Ni siquiera puede afirmarse que en alguno de ellos sea similar.

Dado que España reconoce que se trata de realidades geográfica, política, social y culturalmente complejas, la realidad resultante, la Primavera Árabe, es para la política exterior española un hecho prioritario y una preocupación recurrente. Sin embargo, España ve ahora la situación como antes. Sólo varía el horizonte de la posición normativa de su política. No hay escisión. Porque este horizonte es garantía de apertura y transparencia.

El panorama ha cambiado. Es cierto. España defiende, en consecuencia, que la voluntad popular ha de ser respetada. Como explícitamente lo ha hecho ante la comunidad internacional. Por lo que aconseja que el diálogo haya de mantenerse en términos respetuosos.

Para ello la estrategia no puede ser otra: acompañamiento y persuasión. Generando, a su vez, un capital de confianza. Porque la UE no tiene, ni puede tener en esta ocasión, baraja oculta alguna. Para fomentar el diálogo el habla, las diferentes hablas, España ha mantenido un nivel coherencia plausible. La política española al respecto es clara. Por lo que es defendible: Las manifestaciones de cambio en cada uno de los países en donde se han generado movimientos no previstos, el soporte ha sido siempre una manifestación de la voluntad popular a través de los discursos que, respectivamente, hasta entonces habían sido silenciados o reprimidos. Y esa voluntad se manifiesta a través de la reivindicación de valores inherentes a sus respectivas culturas, historia y tradición. Sin olvidar un factor clave: el papel que las diferentes posiciones religiosas han jugado y la gestión que de estas posiciones se ha hecho. No siempre con resultados internacionalmente homologables.

Hemos comprobado que la situación es mejor en aquellos países con vocación europea, como Túnez, Marruecos o Jordania. Algo de lo que es consciente la diplomacia y la política española. Como conscientes de ello son los teóricos de la revuelta. Dentro o fuera de los correspondientes países. Teóricos o testigos críticos de la revuelta de visión o mirada no siempre similar, aunque a menudo convergente o complementaria. Háblese, por tanto, de periodistas, fotógrafos 0 
militares. Háblese también de escritores o intelectuales. Entre los que han jugado un papel importante los politólogos y los sociólogos. Pero también los antropólogos y, en cierta medida, los filólogos.

Entre las historias de éxito no sólo hay que hablar de Túnez. Otras, que están viviendo procesos de demanda e intervención ciudadana, han reaccionado en sentido positivo, como es el caso de Argelia y Marruecos.

Cuatro años después del inicio de este no siempre fácil camino hacia la transición democrática los países árabes, el mundo árabe contemporáneo, vive un tenso periodo de incertidumbre. Tiene que seguir haciendo frente a la resistencia de la vieja clase política, revestida de un autoritarismo no siempre explícito. Asumido como inevitable, natural, por los sectores de la población más deprimida, culturalmente deficitaria o indigente y menos concienciada. Obstáculos de siempre de fácil superación.

La resistencia al cambio no sólo se sostiene, en consecuencia, por la beligerancia y poder (económico, de influencias y simbólico) de las clases o castas políticas hasta entonces gobernantes. Esa resistencia tiene una fuerza e importancia menos visible cuando el arraigo en la visión de gobierno y gestión ha pasado a formar parte de la normalidad, soporte y equilibrio de la vida cotidiana. Normalidad y equilibrio que se teme perder, si se implantan formas nuevas de gobierno y gestión. Es decir, se teme tanto al cambio, por mucho que las nuevas estructuras coincidan con los deseos 0 aspiraciones generalizas que esas nuevas estructuras están en condiciones de garantizar una mayor participación democrática. Como se teme también que ese cambio conlleve un coste o perjuicio personal imprevisto. En materia de reordenamiento de esquemas mentales como en actitudes o comportamientos.

La verdad y la mentira, como el bien y el mal, no son referentes (conceptos, metas o estados), que tengan una utilidad instrumental homogénea en cada uno de los integrantes de un determinado cuerpo social. El individuo no quiere ser perturbado. Que la aceptación de un polo en detrimento del opuesto le genere conflictos. O su identificación con alguno de ellos. A nivel de relaciones. Como a nivel de conciencias o praxis, religiosa o moral. Se resiste a ser utilizado. Sea o no explícita esa utilización. Sea o no consciente de las turbulencias entorno.

Los gobiernos reconocen, a menudo, como interlocutores válidos a agentes autónomos. Los académicos o intelectuales que nos ocupamos del tema interpretamos y procesamos los estados de opinión: el sentir manifiesto o indirectamente explícito de la ciudadanía para generar textos que ponemos a disposición no sólo de esa ciudadanía, sino también y especialmente, al servicio de la clase y formaciones políticas y ciudadanas, así como al de los gobiernos. Tanto una como otros saben que no intervenimos (o no deberíamos hacerlo) en decisiones que sólo a ellos corresponden. Si bien podemos y debemos hacer una crítica del imparto que esas decisiones posteriormente tengan. En un sentido o en el contrario.

A su vez, y en la medida que ese sentir es cambiante, los textos generados son sometidos a un proceso de verificación recurrente. En ambas direcciones. Son contrastados con el estado de la praxis y con la lectura que de esta praxis hacen los gobiernos. 
Soy consciente de que la posición oficial española, como la de cualquier otro gobierno, no siempre es compartida o coincidente, en parte o su totalidad, con la de la ciudadanía española a través de las formaciones políticas y sindicales. Pero también a través de las organizaciones sociales y otros movimientos no reglados o, en su caso, no regulables. Y la interpretación variada que de estas posiciones críticas o resistentes hacen los medios de comunicación.

Si bien no ha sido ése el caso, entiendo que los responsables de la actual política exterior española en el Mediterráneo son conocedores de estas determinaciones. Aún más, creo que han manifestado su respeto por ellas, siendo dialogante con sus mentores o representantes más visibles 0 cualificados.

\title{
A P É N D ICE
}

\section{Voces. Luz y claridad en el Mediterráneo ${ }^{9}$}

\begin{abstract}
El Mediterráneo es más que un mar, un lago mágico. También es una cultura, una manera de ser, una manera de vivir, de amar, de morir. No es casualidad que haya sido el lugar de nacimiento de la filosofia y la tragedia. El Mediterráneo está hecho para toda suerte de excesos, para la gratuidad, para la belleza y para el espectáculo de la vida. Eso son las gentes del Sur, las gentes de Sicilia, de las islas griegas, del norte de Marruecos, de Túnez y también de Argelia, que lo comprenden y lo viven (Tahar Ben Jelloun)

El Mediterráneo tiene alma mitológica y mística. Pero sobre todo, posee un alma poética. Muchos de los grandes caminos del mar de la literatura salen desde sus puertos o van a morir en sus orillas. Y cada ola escoge una canción. (Javier Reverte)
\end{abstract}

\footnotetext{
${ }^{9}$ Conviene detenerse en este tema, leifmotiv de la filosofía alemana contemporánea y las eventuales influencias que Ortega y Gasset tuvo sobre ella, especialmente en Martin Heidegger: "La presencia de lo presente no tiene una relación con la luz en cuanto tal, en el sentido de la claridad. Pero, la presencia sí está dirigida hacia la luz en el sentido del claro. Lo que esta palabra nos da para pensar se puede aclarar con un ejemplo, supuesto que lo reflexionaremos lo suficiente. Un claro del bosque es lo que es, no sobre la base de la claridad y de la luz que pueden aparecer en él durante el día. También durante la noche persiste el claro. Él indica que: se puede pasar por el bosque en ese lugar. La luminidad (Lichte) en el sentido de la claridad (Hellen) y la luminidad del claro no sólo se distinguen en su asunto, sino también de palabra. Clarear (Lichten) quiere decir: despejar, dejar libre, aligerar. A 'clarear' le pertenece 'ligero' (leicht). Aligerar algo, aliviarlo, quiere decir: dejar de un lado lo que se le opone, llevarlo hacia lo libre, hacia lo sin resistencia. Levar el ancla (den Anker lichten), significa: liberarlo del cercante fondo marino y levantarlo hasta lo libre del agua y del aire". Martín Heidegger, Zur Frage nach der Bestimung der Sache des Denkens (1984). http://www.heideggeriana.com.ar/textos/pregunta_determinacion_pensar.htm, consultado el 22/06/2014; "El clarear (Lichtung) que la obra de arte pone en medio de los entes, es al mismo tiempo un ocultamiento. $Y$ esto no es un juego de artista. Heidegger entiende que lo que la obra (Werk) de arte hace no es un simple obrar (Wirken) en el sentido de un efectuar, de un producir, donde simplemente se estaría manifestando la autoría del artista. En la obra de arte se abre un claro (Lichtung) donde se pone en obra (Ins-Werk-Setzen) la verdad de las cosas". Antonio González, 'Ereibnis' y actualidad: http://www.praxeologia.org/ereignis.html, consultado el 22/06/2014
} 
Desde un destacado y plural corredor, Joan Manuel Serrat o Raimon (Ramón Pelegero), Marina Rossell, Lluís Llach o Maria del Mar Bonet, Joaquín Sorolla o José Luis Checa, Luis Buñuel, Carlos Saura o Pedro Almodovar, Rafael Alberti o Juan Goytisolo, Manuel Vicent o Lorenzo Silva, Ahmed Ararou (por adopción o devoción), ente tantas y tantos otros, han puesto voz al Mediterráneo. Dándole una luz nueva. Resaltando su esplendorosa claridad. Su seductora armonía. Su compromiso y su complicidad. Otra forma de política exterior española.

En el Mediterráneo se resuelve el dilema de la encrucijada: Se puede partir sin haber llegado. Se puede llegar estando.

De José Ortega y Gasset $^{10}$ a María Zambrano ${ }^{11}$, pasando por Martín Heidegger ${ }^{12}$, la luz y la claridad (Klarheit o Lichtung) nos generan claros en el bosque. Un bosque convertido en mar por el que navegan sueños, hechos realidad unos, frustrados otros. Pero que atracan en espacios privilegiados que los acogen. Las migraciones, la movilidad en el Mediterráneo no sólo ha sido horizontal. La historia da fé de ello. Y las huellas que esta movilidad ha dejado en tierras y en poblaciones de origen diferente a los que llegan, se instalan y contaminan.

Luz y claridad del Mediterráneo. La sensibilidad de sus gentes. La acogida e integración de los extraños, sin renunciar a lo propio. La música y la pintura. La arquitectura. El diseño del espacio urbano. Y el del espacio doméstico, la propia casa. Vivos registros, huellas de una historia que es propia.

El paso de pobladores de distintas procedencias, culturas o religiones no siempre fue un problema de imposible resolución. O mejor, el problema surge a posteriori. Cuando la voluntad de integración posterior es selectiva, inclusiva. Y la resistencia originaria se convierte en estímulo para los que llegan.

Esta resistencia originaria deviene en asimilación compleja: integrando los valores de los pueblos previamente existentes. Mezcolanza que es referente de diálogo. Algo que registra los monumentos. Pero también la producción intelectual resultante. Desde la poesía hasta la filosofía y la literatura. La creatividad específica que no encaja en patrones tradicionales. Genuina, tolerante. Profundamente arraigada en valores estéticos, morales y mágicoreligiosos. Descriptores de un espacio aparentemente nuevo, abierto, seductor. Acogedor. Receptivo y respetuosamente crítico.

Sus símbolos son objeto de preciado valor, tengan éstos una historia con valores encontrados o excluyentes. Porque tras el complejo diseño del espacio mediterráneo puede descubrirse al hombre que lo ha diseñado y que se perpetúa en las generaciones que le han reemplazado. La piedra y la poesía

\footnotetext{
${ }^{10}$ El bosque de Ortega y Gasset se inspira en la arboleda que rodea el Monasterio del Escorial. Se refiere a él en sus Meditaciones del Quijote, publicado en 1914.

${ }^{11}$ Claros del bosque de María Zambrano, recopilación de escritos de los años 1964 a 1971 y fechado de 1977, hace referencia al bosque que rodeaba su casa en los últimos años de su vida en la pequeña localidad francesa de La Piéce, junto a la frontera suiza.

12 'El filósofo de la Selva Negra', Martin Heidegger, publica en 1950 Holzwege, (Sendas perdidas, Losada, Buenos Aires, o Caminos del bosque, Alianza Ed., Madrid, Chemins qui ne mènent nulle part, Gallimard, Paris), recopilación conferencias de los años 1935-1946. Este frondoso bosque está precisamente en las inmediaciones de Freiburg.
} 
que evocan son inseparables de la carne que la modela y convirtiera en instrumento prioritario de movilidad y equilibrio. Fijando modelos de relación micro-macro. Soportes de la convivencia con posibilidades de ser transferidos a otros pueblos colindantes. O admirados por sus visitantes o moradores no autóctonos.

La piedra lleva la marca del hombre. Y el hombre no puede ser entendido sin la marca que la piedra ha dejado en él. Es su medio, su entorno. La pantalla de proyección de su imaginario y de sus sentimientos. La seguridad de su identidad. Garante de integridad. Una especie de invasión recíproca no traumática. Pérdida de uno en la otra y viceversa. Circunstancias que permiten ser registradas pasado el tiempo en relatos, que se perpetúan. Fuente de inspiración de historiadores. Pero también de conquistadores, vagabundos o aventureros. De auto-constitución medio-hombre, en definitiva.

El diálogo no es sólo entre piedra y carne. Y manos que acarician esa piedra. Recreándola, remodelándola. Que soportan o se identifican con la imagen que el hombre les asigna. Y que el hombre, en contrapartida, asume, haciendo suyas y respetando las formas propias de esa materia, cargándola de vida, de psique simbólica el conjunto resultante.

Una armonía espacial que conjuga melodías con colores. Que se inspira en las formas de su arquitectura y en los relatos que dan cuenta de su historia y del crisol de culturas que atesoran.

Viajando por un mar que la pasión o la aventura se le sueña sin límite ni destino. Sin fronteras o corredores que la naturaleza haya impuesto. Ni ninguna otra fuerza divina o humana. Entre Granada y Fez. O Alejandría y Estambul. O Roma y Jerusalem. Desde Atenas a Marrakech. O Trípoli. Recorriendo pasajes. Corredores que los sueños no imaginaran. Diseñando mapas. Tierras y espacios. Paisajes. Tensiones que ni la pasión. Ni el odio ni la fruición destruyen. Ecos que ninguna orden silencia. Turbulencias queridas. Provocadas. Encuentros. Ternura y compasión. Algo de lo que sólo pueden hablar poetas y locos. Pintores. Fotógrafos y narradores de historias jamás contadas. Diseñadores de espacios. Para la movilidad en armonía. Para el disfrute doméstico. Para la ternura. Y para el reposo. Para el recuerdo. El respeto y el culto. Más allá de la vida. Más acá de la muerte.

Hablen si no con Cavafis. Pregunten a Cleapatra y Marco Antonio. A Homero. A Caravaggio. Cézanne o Monet. Picasso o Klee. A Fernand Bruadel o a Albert Camus $^{13}$. Y hablen especialmente con tantos otros que forman parte de la letra pequeña que sólo leen los viajeros. Conocen bien los habitantes de los pueblos o ciudades. No siempre ricas unas y otros. En sabiduría. O en tesoros que no siempre la avaricia acumula. Historias ocultas, que trasciende. Olvidadas. Abandonadas. Destruidas. Por guerreros o cruzados, sacerdotes o príncipes, reyes o emperadores, senadores o tribunos. Por quienes han sido impotentes

\footnotetext{
${ }^{13}$ Albert Camus creó en 1938 la revista Rivages, en cuya presentación escribíó: "Hombres jóvenes, en una tierra joven, proclaman su apego a esos pocos bienes perecederos y esenciales que dan un sentido a neustra vida: mar, sol y mujeres en la luz". El Boletín de la Casa de Cultura de Argel, publicación de los 30., se llamaba precisamente Jeune Mediterranée. Camus fue uno de sus principales animadores. En sus primeros escritos de esta época, Noces o L'Été, se lee, entre otros textos los siguiente: "La carrera de los jóvenes por las playas del Mediterráneo nos acerca a los magníficos gestos de los atletas de Delfos"
} 
de leer sólo aquellos textos con voluntad de permanencia. En los templos o en las escuelas. En parlamentos. En libros, que sólo cuentan e interpretan la voluntad de los conquistadores. De los vencedores.

La letra pequeña es patrimonio del pueblo. El mismo que no la olvida. Que sabe de lágrimas. De dolor y de hambre. De opresión y de muerte. El mismo que reaccionada sin esperar autorización de nadie. Cuando nadie menos lo espera. Letra pequeña, grabada en la memoria de los pueblos y de sus gentes. En los registros que de esa memoria son testigos monumentos populares. Escondidos o reprimidos diseños.

La (pseudo) arquitectura del conocimiento y del saber. La historia oficial no siempre coincide con la historia real del Mediterráneo. Historia a menudo por escribir. Para que la lean quienes deciden el destino de los pueblos. Y administran su voluntad. Voluntad que produce perplejidad cuando éste irrumpe en la escena pública con una violencia y visibilidad desconocidas.

Es el repentino despertar de la dignidad. La madurez que un pueblo silenciado ha hecho valer. Sin esperar consignas. Vengan o no de un líder, laico o religioso. Y ha reclamado lo que es suyo. Sólo suyo. Lo obvio: Libertad, justicia e igualdad. Porque su dignidad es su inviolable y más preciado patrimonio.

Cuando se conoce a los personajes se puede hablar de ello con más propiedad. Creo, en consecuencia, que los actuales diseñadores y gestores de la política exterior española son mujeres y hombres suficiente $y$ adecuadamente formados e ilustrados. Con sensibilidad manifiesta para entender e integrar en sus programas los aspectos previamente señalados. No de otra manera podría entenderse el éxito que, al respeto y con matices, se reconoce a España en su política hacia la actual situación que viven pueblos y naciones en el Magreb y Oriente Próximo. Situación históricamente relevante y que ha convenido en llamarse Primavera Árabe. 


\section{BIBLIOGRAFIA}

ABUFALIA, David (2003), El Mediterráneo en la historia. Barcelona, Crítica.

AMIN, Samir (1989), El Mediterráneo en el mundo: la aventura de la transnacionalización. Madrid, IEPALA.

BALTA, Paul (2005), El Euromediterráneo. Madrid, Ediciones del Oriente y el Mediterráneo.

BLANC ALTEMIR, Antonio (Editor) (1999). El Mediterráneo: un espacio común para la cooperación, el desarrollo y el diálogo intercultural. Madrid, Tecnos.

TAHAR BEN JELLOUN, Tahar (2011), La Primavera Árabe, Alianza, Alianza, Madrid

BRAUDEL, Fernand (1989), El Mediterráneo, Madrid, Espasa Calpe.

CANO PÉREZ, María José y MUÑOZ, F. A. (1997), Hacia un Mediterráneo pacífico. Granada, Universidad de Granada.

CARPENTIER, Jean y LEBRUN, François (2008), Historia del Mediterráneo. Barcelona, Base.

CESEDEN (Monografías) (2003), El Mediterráneo: proceso de Barcelona y su entorno después del 11 de septiembre. Madrid, Ministerio de Defensa, Secretaría General Técnica.

JAÉN, Manuel y MARTíNEZ, Fernando (eds.) (2002), El Mediterráneo: confluencia de culturas. Almeria, Universidad de Almeria.

KHADER, Bichara (dir) (1994), L'Europe et la Méditerranée. Géopolitique de la proximité. París, L'Harmattan.

MARTÍNEZ DALMAU (2006), Europa y el Mediterráneo, Perspectivas del diálogo euromediterráneo. Valencia, UV.

MATVEJEVIC, Predrag (1991), Breviario mediterráneo. Madrid, Anagrama.

MIRA, Eduard (1991), El Mediterráneo, entre Europa y el Islam. Valencia, Prensa Valenciana.

MUNIF, Abderrahmán (2001), Al este del Mediterráneo. Madrid, Ediciones de Oriente y el Mediterráneo.

NAÏR, Sami (1997), Mediterráneo hoy: entre el diálogo y el rechazo, Barcelona, Icaria.

NAÏR, Sami, et alii (2002), El Mediterráneo y la Democracia, Voces Libres, 2008.

NORWICH, John J. (2008), El Mediterráneo, Un mar de encuentros y conflictos entre civilizaciones. Madrid, Ariel.

NOUSCHI, André (2008), El Mediterráneo en el siglo XX. Granada, UGR.

PÉREZ BELTRÁN, Carmelo y MUÑOZ, Fco. A. (2003), Experiencias de paz en el Mediterráneo. Granada, Ed. Universidad de Granada.

PORCEL, Baltasar (1996), El Mediterráneo: una globalidad emergente. Madrid, Universidad Complutense de Madrid.

RACIONERO, Luis (1996), El mediterráneo y los bárbaros del norte. Esplugas de LLobregat, Barcelona, Plaza y Janés.

RUIZ DOMÉNEC (2004) José Enrique (2004), El Mediterráneo: historia y cultura. Barcelona, Península.

SAID, Edward (2001), Fuera de lugar. Barcelona, Mondadori.

SID AHMED, Abdelkader (1998), El Mediterráneo, de la integración a la fragmentación: los intercambios de la Antigüedad a nuestros dias. Datos, fundamentos y perspectivas. Barcelona, CIDOB.

TILLION, Germaine (1993), La condición de la mujer en el área mediterránea. Barcelona, Nexos.

VANGUARDIA. DOSSIER (2005), Mediterráneo. El mar que uno y separa. Barcelona, Ed. Vanguardia. 
Mapas Históricos del Mediterráneo:

http://explorethemed.com/Defaultes.asp

\section{Bibliografía Básica sobre la Union Europea:}

http://www.madrid.org/cs/Satellite?blobcol=urldata\&blobheader=application\%2Fpdf\&blobheader name1=Content-

disposition\&blobheadername2=cadena\&blobheadervalue1=filename\%3DBibliograf\%C3\%ADa+ $\mathrm{b} \% \mathrm{C} 3 \% \mathrm{~A} 1$ sica+de+la+Uni\%C3\%B3n+Europea.pdf\&blobheadervalue2=language\%3Des\%26sit e\%3DMPDE\&blobkey=id\&blobtable=MungoBlobs\&blobwhere=1352816522374\&ssbinary=true

\section{Fuentes on-line}

http://www.atalayar.com/content/\%E2\%80\%9Ccuanto-mejor-le-vaya-marruecos-mejor-leir\% $\%$ C 1 -

espa\%C3\%B1a\%E2\%80\%9D?fb_action_ids=10203207482021659\&fb_action_types=og.likes\&f b_source=other_multiline\&action_object_map=[674176619322138]\&action_type_map=[\%22og.I ikes\%22]\&action_ref_map=[]

https://www.youtube.com/watch?v=z5I2Z8ISKY8

http://www.politicaexterior.com/?limit=pe\&s=magreb+mediterraneo

http://proximooriente.blogspot.co.uk/2014/06/revueltas-y-transiciones-en-

oriente.html?utm_source=feedburner\&utm_medium=email\&utm_campaign=Feed:+PrximoOrien te+(Pr\%C3\%B3ximo+Oriente)

Que inventen ellos

http://es.wikipedia.org/wiki/\%C2\%A1Que_inventen_ellos!

\section{Madariaga y La Construccion Europea}

http://www.fundacionfaes.org/file_upload/publication/pdf/20130425184511salvador-de-

madariaga-y-la-construccion-europea.pdf

\section{España y Marruecos: Dimensión Africana}

http://www.atalayar.com/content/espa\%C3\%B1a-y-marruecos-refuerzan-su-

cooperaci\%C3\%B3n-apostando-por-\%E2\%80\%9Cla-dimensi\%C3\%B3n-africana\%E2\%80\%9D

\section{Marruecos, mundo emergente}

http://www.abc.es/cultura/libros/20130927/abci-lorenzo-silva-marruecos-mundo-

201309261835.html

Sartre: la autencidad y la violencia

http://www.nexos.com.mx/?p=3631

El Mediterráneo vive un momento crítico en su historia

http://www.elcultural.es/version_papel/LETRAS/32787/David_Abulafia

\section{De tanto mirar Europa se nos olvido el Mediterráneo}

http://revistadeletras.net/david-abulafia-de-tanto-mirar-europa-se-nos-olvido-el-mediterraneo/

\section{Viaje al mar de la literatura}

http://www.mgar.net/docs/reverte.htm 